\title{
Safety Practice and Associated Factors Among Waste Handlers in Governmental Hospitals in Addis Ababa, Ethiopia
}

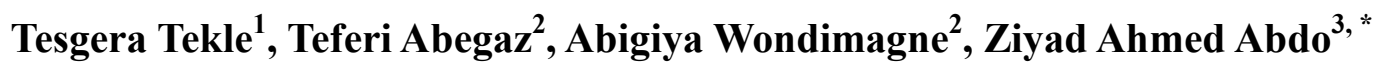 \\ ${ }^{1}$ Addis Ababa Health Bureau, Department of Health Extension Program and Primary Health Care Directorates, Addis Ababa, Ethiopia \\ ${ }^{2}$ Department of Public Health, Addis Ababa University, Addis Ababa, Ethiopia \\ ${ }^{3}$ Department of Hygiene and Environmental Health, Ethiopian Ministry of Health, Addis Ababa, Ethiopia
}

Email address:

ttekle2010@gmail.com (T. Tekle), teferiabegaz@gmail.com (T. Abegaz), abitowon@gmail.com (A. Wondimagne), ziyadahm1982@gmail.com (Z.A. Abdo)

${ }^{*}$ Corresponding author

\section{To cite this article:}

Tesgera Tekle, Teferi Abegaz, Abigiya Wondimagne, Ziyad Ahmed Abdo. Safety Practice and Associated Factors Among Waste Handlers in Governmental Hospitals in Addis Ababa, Ethiopia. European Journal of Preventive Medicine. Vol. 9, No. 4, 2021, pp. 107-113.

doi: $10.11648 /$ j.ejpm.20210904.12

Received: May 1, 2021; Accepted: June 26, 2021; Published: July 9, 2021

\begin{abstract}
Health facilities generate different types of wastes characterized as hazardous wastes and most of them are infectious, toxic, harmful and carcinogenic. Medical Waste handlers faced massive exposure to hazardous wastes and occupational accidents as a result of manual handling of waste and working under unfavorable conditions. This indicates that waste handlers are often at high risk of occupational injuries. In Ethiopia there are limited studies and updated information concerning this issues. To fill the gap this study was intended to assess safety practices and associated factors among selected public hospital waste handler in Addis Ababa, Ethiopia, 2019. An institutional based cross- sectional study design was used to conduct the study. All waste handlers of selected public hospitals in Addis Ababa were included in the study. The data was collected via interview using structured questionnaire. Bivariate and multi variable logistic regressions were employed to identify the predictor variables. Statistical significance was considered at $\mathrm{P}<0.05$ with adjusted odds ratio calculated at $95 \%$ CI. The prevalence of current safety practice among public hospital waste handlers was found to be $44.1 \%(95 \% \mathrm{CI} ; 37.3-51.0)$. Respondents with good knowledge ( $\mathrm{AOR}=4.7 ; 95 \% \mathrm{CI}$ : 1.9, 11.5), having good supplies (AOR=6.78; 95\%CI: 2.2, 20.7) had higher odds of adherence to safety practices compared to their counterparts. The study shows that the prevalence of safety practice is low. Knowledge of waste handles on safety measures and availability \& accessibility of safety materials is the determinant factors for safety practice while handling waste. To sustain good safety practice adequate per-service and inservice training should be in place to increase their knowledge and practice about safety precautions and similarly providing enough safety materials is recommended to strength adherence to safety practice among hospital waste handlers.
\end{abstract}

Keywords: Safety Practice, Determinant Factors, Waste Handlers, Public hospitals, Addis Ababa, Ethiopia

\section{Introduction}

Workers and waste pickers handling solid waste throughout the world are exposed to occupational health and accident risks related to the content of the materials they are handling, emissions from those materials, and the equipment being used [1]. About $85 \%$ of wastes produced in health facilities are non-hazardous and the remaining $15 \%$ of health care waste is characterized as hazardous and can pose a number of health risks $[2,3]$. Hazardous wastes which are generated from health facilities are mostly infectious, toxic, harmful and carcinogenic and affect health care workers, waste handlers and laundry personnel [3].

Medical Waste handlers faced massive exposure to hazardous wastes and occupational accidents as a result of manual handling of waste and working under unfavorable conditions $[4,5]$. Waste handlers are often at high risk than health care professionals [6]. Because health care 
professionals produce the waste and they throw it in the garbage. However waste handlers handle it extensively throughout and mostly very little attention is given for their safety $[3,6]$.

Medical waste handlers who are working in collection, transportation, cleaning and disposal of medical wastes in health institutions have been consistently shown to have higher prevalence of $\mathrm{HBV}$ and $\mathrm{HCV}$ infection [7-9]. Different study shows that the prevalence of HBV was higher (48.6\%) among medical waste handlers with the history of blood and body fluid splash and needle stick injuries [7].

Health care waste should be collected and transported in a safe way to avoid unnecessary exposure $[10,11]$. But about $58.8 \%$ and $41.2 \%$ of waste handlers were exposed to blood and body fluids due to carrying over filled waste bags which increase the risk of infection for different pathogens like HBV, HCV and HIV/AIDs and about $47 \%$ of medical waste handlers had at least one accidental Sharp injury because of improperly discarded needle and sharp materials [7, 12].

Unavailability or shortage of personal protective devices aggravates the risk of acquiring infection while exposed to hazardous wastes $[4,13,14]$. Waste handlers usually do not wear sufficient protective clothing during waste handling which increases the potential risk of accidents $[12,15,16]$.

The study done in Eastern Ethiopia also reviled that 30\% of waste handlers were exposed to any Sharpe materials due to improper handling, poor waste segregation and poor utilizations of personal protective equipment's [4]. However few studies are conducted regarding to the prevalence of safety practice among hospital waste handlers in Ethiopia. There is very few data on the prevalence of safety practice and its associated factors among medical waste handlers in the country. Hence the intended study was determined the prevalence of safety practice and its associated factors among hospital waste handlers, which in turn enables to understand the overall situations of safety practice and minimize those factors that hinder safety practice of hospital waste handlers.

\section{Methodology}

\subsection{Study Design and Setting}

An institutional based quantitative cross-sectional study design was used to assess safe waste handling practice among waste handler in health institution in Addis Ababa. According to EDHS 2016 the city had high population density with a total of approximately $3,515,678$. The city had been divided in to 10 sub-cities and 117 woredas. Generally in Addis Ababa there were approximately 1,500 waste handlers working in government hospitals. In selected hospitals there were around 572 wastes handlers.

\subsection{Population and Eligibility Criteria}

Source population was all waste handlers working in public hospitals in Addis Ababa. While study population was all waste handlers enrolled in the selected government hospitals, present on duty during data collection period.
Waste handlers who were seriously ill during the time of data collection and those with hearing impairments were excluded from study.

\subsection{Sample Size and Sampling Strategy}

The sample size for prevalence of safety practice was calculated using single population proportion formula. Assuming 95\% confidence level of $Z_{\alpha} / 2=1.96, \mathrm{~d}=$ margin of error of 0.05 and using proportion of $50 \%$ the sample size was calculated as follow:

$$
n=\frac{\left(Z_{\alpha} / 2\right)^{2} P(1-P)}{d^{2}}
$$

Based on this information, the sample size calculated was 384 ; however the total population size of the study area were less than 10,000 we applied the population correction formula and get sample size of 230 . Finally adding $10 \%$ nonresponse rate, 253 sample sizes were considered for this study.

From total of 11 government hospitals found in Addis Ababa under the city administration, five general Hospitals were selected purposely. The purpose of selecting these hospitals were because the remaining five were under federal government which have different capacity and work load as compared to general hospitals. And one under the city government was not general hospital and not as sufficient as the rest hospitals to be selected as study area. The calculated sample size was proportionally allocated to each selected hospitals based on the number of total waste handlers they had. To grip the total participants from each selected health institution, simple random sampling technique was used.

\subsection{Study Variables}

1) Dependent Variables: Safety practices of waste handler.

2) Independent Variables: Socio demographic factors, Knowledge about safety, Health care waste handlers risk perceptions, Work related factors, Availability of equipment in the working area, Organizational factors.

\subsection{Data Collection Tools and Procedure}

The questionnaire was developed by principal investigator after reviewing WHO, Ethiopian Ministry of Health infection prevention guide line and different literatures with modification based on research objectives. Prior to the actual data collection the questionnaire was adjusted and corrected based on the pre-test result and the final questionnaire was translated to Amharic and then back to English to insure its consistency. Finally two environmental health science professionals conducted face to face interview to collect the data using Amharic version questionnaire. For data quality control purpose, the data collectors were trained before the data collection and supervised during the data collection period. Supervisors made spot-checking and reviewing the completed questionnaires to ensure completeness and consistency of the information collected. Those incomplete 
questionnaires were omitted from the analysis.

\subsection{Data Management and Analysis}

The data was entered into Epi info version 7, then, the data was exported to SPSS version 22 for data management and analysis. Descriptive statistics, percentages and mean was carried out. Hence, bivariate logistic regression was performed to identify variable that associate with dependent variables. Variables with $P<0.2$ during bivariate analysis were included in multiple logistic regression to identify factors associated with safety practice of waste handlers by controlling potential confounding variables. Statistical significance was considered at $P<0.05$ to see the determinant factors for safety practice with adjusted odds ratio calculated at $95 \% \mathrm{CI}$.

\section{Result}

\subsection{Socio-demographic Characteristics of Respondents}

A total of 242 waste handlers were participated in this study, making a response rate of $95.6 \%$. All respondents were female with mean age group of $32 \pm \mathrm{SD}$ of (2.2) years. About $141(58.7 \%)$ hospital waste handlers were married, out of respondents $142(58.7 \%)$ had completed secondary and above educational level. Majority of them $211(87.2 \%)$ had less than 5years work experience and 209 (86.4\%) of them had income level $\leq 1500$ birr per month. Around $49.6 \%$ of waste handlers were working their job in regular time $(8 \mathrm{hrs}$ per a day). About $48(19.8 \%)$ and $35(14.5 \%)$ were from emergency and medical respectively. More detail about socio-demographic characteristics is depicted in Table 1.

Table 1. Socio demographic characteristics of medical waste handlers in selected public hospitals of Addis Ababa, Ethiopia May, 2019 (N=242).

\begin{tabular}{|c|c|c|c|}
\hline Variable & Category & frequency & percentage \\
\hline \multirow{4}{*}{ Age } & $\leq 25 \mathrm{yrs}$ & 39 & 16.1 \\
\hline & $26-30 y r s$ & 66 & 27.3 \\
\hline & $31-35 y r s$ & 70 & 28.9 \\
\hline & $>35 \mathrm{yrs}$ & 67 & 27.7 \\
\hline \multirow{4}{*}{ Marital status } & Married & 141 & 58.7 \\
\hline & single & 91 & 37.6 \\
\hline & Widowed & 3 & 1.2 \\
\hline & Divorced & 6 & 2.5 \\
\hline \multirow{2}{*}{ Educational level } & Primary & 100 & 41.3 \\
\hline & Secondary and Above & 142 & 58.7 \\
\hline \multirow{2}{*}{ Service Year } & $\leq 5 \mathrm{yrs}$ & 211 & 87.2 \\
\hline & $>5 \mathrm{yrs}$ & 31 & 12.8 \\
\hline \multirow{2}{*}{ Monthly Income } & $\leq 1500$ & 209 & 86.4 \\
\hline & $>1500$ & 33 & 13.6 \\
\hline \multirow{2}{*}{ Working hours per day } & $\leq 8 \mathrm{hrs}$ & 120 & 49.6 \\
\hline & $>8 \mathrm{hrs}$ & 122 & 50.4 \\
\hline \multirow{8}{*}{ Working departments } & Out patient & 34 & 14 \\
\hline & Emergency & 48 & 19.8 \\
\hline & Laboratory & 30 & 12.4 \\
\hline & Surgery & 25 & 10.3 \\
\hline & Medical ward & 35 & 14.5 \\
\hline & Pediatric & 26 & 10.7 \\
\hline & Gyn./Obs. & 33 & 13.6 \\
\hline & Others & 11 & 4.5 \\
\hline
\end{tabular}

\subsection{Knowledge of Hospital Waste Handlers about Safety Practice}

Out of 242 respondents asked six knowledge questions with yes or no answer to assess their knowledge about safety practice $176(72.7 \%)$ of them knew as they are at risk of hospital associated infections. Nearly $70 \%$ of them knew that washing hand with plain soap and water inhibit resident flora and $69 \%$ of them knew that glove should be used not only during anticipation of blood or body fluid exposure. Majority of the respondents 167 (69\%) knew vaccinated for HBV vaccine was a means of prevention from infection. Nearly $60 \%$ of them hand knowledge of post-exposure prophylaxis. A total of $142(58.6 \%)$ of the study participants had good knowledge of safety practice.

\subsection{Attitude of Hospital Waste Handlers about Safety Practice}

From total of 242 respondents asked five attitude questions with Likert-type scale options ranging from "strongly disagree" to "strongly agree" answer to assess their attitude about safety practice majority of them $141(58.3 \%)$ had agreed on that washing hands with soap or alcohol based antiseptic decrease the risk of transmission of hospital acquired infections. Nearly $40 \%$ of them disagreed on that glove provides complete protection against acquiring/transmitting hospital acquired infections and $89(36.8 \%)$ disagreed on that hand washing is unnecessary when gloves are worn. About (33.5\%) of the study participants disagreed on that frequent hand washing damages skin and causes cracking, dryness, irritation and dermatitis. A total of 114 (47\%) of the study participants had 
disagreed on that hospital waste handler have a very low risk of acquiring infection from improperly disposed hospital wastes. More than $50 \%$ (125) of the study participants had good attitude towards safety practice.

\subsection{Organizational Factors Affecting Safety Practice of Hospital Waste Handler}

Out of 242 waste handlers interviewed 105 (43.4\%) of them had gained any types of training about safety practice, $101(41.7 \%)$ of them supervised regularly by the organization and $36(14.9 \%)$ of them have got both training and regular supportive supervision. (See figure 1)

\subsection{Availability of Personal Protective Equipment's Among Waste Handler}

Organizational factors that may affecting safety practice

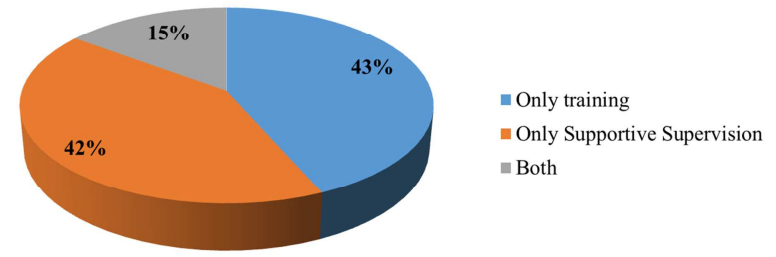

Figure 1. Organizational factors affecting safety practice of hospital waste handlers in Addis Ababa, Ethiopia, 2019.
A total of 242 respondents were interviewed to check availability of personal protective equipment's in there facility. From thus interviewed almost all $233(96.3 \%)$ of them respond that glove were available, hence $229(94.6 \%)$ of them respond that as gown were available. Almost above $60 \%$ of them also respond mask were available. Nearly $10 \%$ of them answered that caps were available and $14(5.8 \%)$ of them respond that goggle were available at the facilities. All respondents reported that there were no boots available at the hospitals during data collection period.

\subsection{Safety Practice of Hospital Waste Handler}

Only $19(7.9 \%)$ of respondents were washed their hands at all the selected critical time of hand washing practice. About $61(25.2 \%)$ of them wore at least four and above four types of personal protective equipment's during handling of health care waste. $150(62 \%)$ of the respondents were immunized for HBV. Nearly $60 \%$ of them separated hazardous and non-hazardous waste during collection and transportation of hospital waste to disposal site. About 215 $(88.8 \%)$ of them used separated colour coded bine system during collection. But $166(68.6 \%)$ were mixing waste stored at separated bine during transportation of hospital waste to disposal site. Only $61(25.2 \%)$ of them asked decontamination of hazardous waste before disposal. In general, about $107(44.2 \%)$ respondents practicing safely and the rest $135(55.8 \%)$ were within unsafe practice. See Table 2.

Table 2. The prevalence of safety practice among waste handlers in public hospital in Addis Ababa, Ethiopia 2019.

\begin{tabular}{|c|c|c|c|}
\hline Safety Practices & Possible responses & Frequency & Percentage \\
\hline \multirow{2}{*}{ Hand washing at five critical time } & Yes & 19 & 7.9 \\
\hline & No & 223 & 92.1 \\
\hline \multirow{2}{*}{ Wore at least four and above four of personal protective equipment } & Yes & 61 & 25.2 \\
\hline & No & 181 & 74.8 \\
\hline \multirow{2}{*}{ Immunized for $\mathrm{HBV}$} & Yes & 150 & 62 \\
\hline & No & 92 & 38 \\
\hline Separate hazardous and non-hazardous waste & Yes & 139 & 57.4 \\
\hline \multirow{2}{*}{ Use color coded bin system } & Yes & 215 & 88.8 \\
\hline & No & 27 & 11.2 \\
\hline \multirow{2}{*}{ Mix waste stored in a separate bin during transportation } & Yes & 166 & 68.6 \\
\hline & No & 76 & 31.4 \\
\hline \multirow{2}{*}{ Ask decontamination of waste before disposal } & Yes & 61 & 25.2 \\
\hline & No & 181 & 74.8 \\
\hline \multirow{2}{*}{ Over all Safe practice } & Yes & 107 & 44.1 \\
\hline & No & 135 & 55.9 \\
\hline
\end{tabular}

\subsection{Factors Associated with Safety Practice of Waste Handlers}

Bivariate and multi variable analysis were conducted to see the association of one independent variable with the dependent variable. Based on this, variables significant at least at $P<0.2$ during bivariate analysis were included in the multivariate logistic regression analysis to see the association of variables with safety practice of hospital waste handlers by controlling confounding variables. After computing multivariate analysis, only knowledge of the respondents and availability of safety supplies remained significantly associated with safety practice of hospital waste handlers after controlling for the confounding variables in the regression model. More detail about associated factors is depicted in Table 3. 
Table 3. Logistic regression analysis result on safety practice among hospital waste handlers of Addis Ababa, Ethiopia, 2019.

\begin{tabular}{|c|c|c|c|c|c|}
\hline \multirow{2}{*}{ Variables } & \multirow{2}{*}{ Category } & \multicolumn{2}{|c|}{ Safety practice } & \multirow{2}{*}{ COR $(95 \% C I)$} & \multirow{2}{*}{$\operatorname{AOR}(95 \% C I)$} \\
\hline & & Yes & No & & \\
\hline \multirow{3}{*}{ Age } & $\leq 25 \mathrm{yrs}$ & 8 & 21 & $0.38(0.14-0.99)$ & $0.2(0.06-0.66)$ \\
\hline & $26-30 \mathrm{yrs}$ & 22 & 34 & $0.64(0.31-1.35)$ & $0.44(0.18-1.07)$ \\
\hline & $\geq 36 \mathrm{yrs}$ & 30 & 30 & 1 & 1 \\
\hline \multirow{2}{*}{ Working hours per day } & $\leq 8 \mathrm{hrs}$ & 42 & 62 & 1 & 1 \\
\hline & $>8 \mathrm{hrs}$ & 48 & 52 & $1.36(0.78-2.37)$ & $1.37(0.68-2.72)$ \\
\hline \multirow{3}{*}{ Working departments } & out patient & 10 & 22 & 1 & 1 \\
\hline & surgery & 10 & 10 & $2.2(0.82-5.87)$ & $1.43(00.37-5.48)$ \\
\hline & medical ward & 16 & 14 & $2.5(0.89-7.08)$ & $1.85(0.55-6.24)$ \\
\hline \multirow{2}{*}{ Knowledge } & Good knowledge & 80 & 62 & $6.7(3.15-14.25)^{*}$ & $4.7(1.9-11.5)^{* *}$ \\
\hline & Poor knowledge & 10 & 52 & 1 & 1 \\
\hline \multirow{2}{*}{ Attitude } & positive attitude & 55 & 52 & $1.87(1.06-3.28)$ & $0.94(0.46-1.94)$ \\
\hline & Negative attitude & 35 & 62 & 1 & 1 \\
\hline \multirow{2}{*}{ Availability of safety materials } & good & 26 & 5 & $8.85(3.24-24.2)$ & $6.7(2.2-20.7)^{* *}$ \\
\hline & poor & 64 & 109 & 1 & 1 \\
\hline \multirow{2}{*}{ Training } & trained & 30 & 21 & $2.21(1.16-4.22)$ & $1.74(0.78-3.88)$ \\
\hline & not trained & 60 & 93 & 1 & 1 \\
\hline
\end{tabular}

**Significant at $\mathrm{p}<0.01, \mathrm{COR}$ : crude odd ratio, AOR: Adjusted odd ratio, CI: Confidence interval

\section{Discussion}

The finding of this study shows that $58.6 \%$ of the study participants had good knowledge on safe medical waste handling practice. The prevalence of personal protective equipment utilizations among the study participants was 25.2 and $62 \%$ of them disposed hazardous and non-hazardous wastes separately. About $88.8 \%$ of them used appropriate color coded bin system for segregation of medical wastes. Sixty two percent of them were immunized for HBV. Only $7.9 \%$ of them practice hand washing at the selected five critical time. The overall current prevalence of safety practice among hospital waste handlers in this study was $44.1 \%$.

Adequate knowledge is a key factor for effective safe handling of medical wastes $[17,18]$. However in this study only $58.6 \%$ of the study participants have good knowledge of safe medical waste handling practice. The result was higher than the finding from Indian and metropolitan city of Pakistan in which only $27.9 \%$ and $34 \%$ of the study participant had good knowledge of safe waste handling practice respectively $[19,20]$. This might be due to the difference in the study time, the setting in which the study was conducted was at general hospitals and might be due to the implementation of different initiatives and in-service training was conducted by infection prevention and patient safety focal person in this study.

In principle all medical waste handlers should properly utilize personal protective equipment during handling of medical wastes [4, 21]. However in this study $25.2 \%$ of medical waste handlers were properly utilizes personal protective equipment. The result was better than the study done in tertiary care health facilities at metropolitan city of Pakistan and Shiraz, Iran hospitals in which 15\%, 22.8\% of waste handlers were utilized personal protective equipment properly $[19,22]$. This difference might be due to the implementation of different initiatives by the ministry of health like CASH and infection prevention and patient safety and increase in knowledge of hospital acquired infections among medical waste handlers.

In general all medical wastes should be segregated properly based on their types in a color coded bin assigned for them and transported to disposal site separately [4, 23, $24]$. In this study about $88.8 \%$ of the study participants used color coded bin for proper waste segregation and transportation of waste to disposal site. The result was lower than the study done at Debre Markos in which $90.9 \%$ of medical waste handlers practice proper segregation and transportation of medical wastes [21]. This difference might be due to the difference in shortage of supplies and low attention given.

In addition Immunization for $\mathrm{HBV}$ for medical waste handlers was also a major safety practice to prevent them from infection. However in this study $62 \%$ of the study participants were vaccinated. This finding was higher than the study done at Turkey in which only $27.5 \%$ of the study participants were immunized for HBV [25]. This difference might be due to that only waste handlers with the history of Sharpe injury and with blood and body fluid contact were immunized for HBV. But in our case all waste handlers working in hospitals with or without any history of contact have the chance of getting immunized for HBV. This finding was also higher than the study done at Debre Markos in which only $20 \%$ of the study participants were vaccinated for HBV [21]. This difference might be due to the setting in which the study was conducted and difference in availability of immunization vaccine.

The prevalence of safety practice among hospital waste handlers in this study was $44.1 \%$. This finding was comparable with research done in Gonder town waste collectors which was 253 (45\%). This similarity might be due to the study design they used which was cross sectional type. The finding was higher as compared with the study done in Shiraz, Iran [22]. This difference might be due to the difference in the study design, setting and time of the study and also the implementation of different reforms by federal ministry of health at hospital like infection prevention and 
patient safety which were promoting safety practice of hospital waste handlers. The number of participants with good safety practice reported in the finding was lower than the study done at KwaZulu-Natal (50\%) [18]. This difference might be due to the study setting and time. Also the finding was lower than the findings from Cameroon in which 100\% of the medical waste handlers used all the appropriate protective gears [26]. This difference might be due to the study setting, difference in knowledge of hospital waste handlers and attention given to safety by governing body. The finding was also lower than the finding from DebreMarkos (80\%) [21]. This difference might be due to the difference in the lower sample size they used.

Multivariable logistic regression revealed that knowledge of respondents and availability of supplies had significant association with safety practice. The odds of safety practice among waste handlers with good knowledge had 4.7 times higher than those who had poor knowledge; (AOR=7, 95\% CI; 1.9-11.5)). This was similar with the study done in DebreMarkos [21] which showed that waste handlers with good knowledge had more practicing safety as compared to those with poor knowledge. The finding of this study was inconsistent with study done in South India [20]. The difference could be due to the difference in study settings which was undertaken at tertiary care hospital and the sampling techniques they used which was purposive sampling which may introduce selection bias and that the knowledge acquired may not be necessary translated in to practice. The odds of safety practice among waste handlers with adequate supplies were 6.7 times higher than those with lack of supplies; (AOR=6.7, 95\%CI; 2.2-20.7). This finding was in line with studies conducted in DebreMarkos [27] in which those respondents with adequate supplies had good safety practice. This similarity might be due to attention given by ministry of health and hospital administration in fulfillments of the required supplies and inputs.

\section{Conclusion and Recommendation}

This study indicate that the level of safety practice was low among hospital waste handlers in relation to waste handling and safety, which may increase the chance of nosocomial infection and occupational accidents. According to this study, knowledge of study participants and availability of safety material are the determinant factors for safety practice in the hospital. To tackle this problem, giving pre-service and inservice training need to be in place which strength their knowledge about safety precautions and similarly availing adequate safety supplies should be implemented to increase adherence to safety practice among hospital waste handlers.

\section{Abbreviations}

EDHS: Ethiopian demographic and health survey; HBV: Hepatitis B virus; HCV: Hepatitis B virus; HIV/AIDS: Human Immunodeficiency Virus/Acquired Immune Deficiency Syndrome; SD: Standard Deviation; SPSS:
Statistical program for social science; WHO: World Health Organization.

\section{Declaration}

\section{Authors' Contribution}

TT hypothesized and developed objective, managed database development $\&$ analysis and revised the manuscript. TA \& AW was responsible for assist in data analysis and assisted in manuscript revision. ZAA assisted in data analysis and primarily wrote manuscript. All authors read and approved the final manuscript.

\section{Availability of Data and Materials}

The datasets used and/or analyzed during the current study are not publicly available, but are available from the corresponding author on reasonable request.

\section{Ethics Approval and Consent to Participate}

Ethical clearance was obtained from Research and Ethics Committee (REC) of School of Public Health, Addis Ababa University. A written consent was also obtained from Addis Ababa city Administration health Bureau. Permissions were secured from each hospital selected for the study. Informed verbal consent was obtained from respondents after explaining the objectives of the study including potential harms and benefits.

\section{Competing Interest}

The authors declare that they have no competing interests.

\section{Authors' Details}

Addis Ababa health bureau, department of Health extension program and primary health care directorates, Addis Ababa, Ethiopia, Addis Ababa University, department of public health, Addis Ababa, Ethiopia, Ethiopian Ministry of health, department of Hygiene and Environmental Health, Addis Ababa, Ethiopia

\section{Acknowledgements}

Our heart-felt gratitude goes to the Addis Ababa School of Public Health College of Health Science library staff for their support while I referring different thesis kept in the library. We would like to thank the selected government hospitals administrative workers who were assist me to get information about the number of waste handlers that help me to design my study sample size and appropriate procedure. We are grateful to all data collectors, supervisors and study participants who took part in the study.

\section{References}

[1] Cointreau S. Occupational and Environmental Health Issues of Solid Waste Management Special Emphasis on Middle- and Lower-Income Countries. Urban papers. 2006. 
[2] WHO. Health care wastes, key facts. 2018. Available from: https://www.who.int/news-room/fact-sheets/detail/health-carewaste. [Last date accessed, April 5, 2021].

[3] World Health Organisation, Emmanuel J, Pieper U, Rushbrook $\mathrm{P}$, Stringer R, Townend W, et al. Safe management of wastes from health-care activities. 2014; 329. Available from: http://apps.who.int/iris/bitstream/10665/85349/1/978924154856 4 _eng.pdf.

[4] Alemayehu T, Worku A, Assefa N. Medical Waste Collectors in Eastern Ethiopia are Exposed to High Sharp Injury and Blood and Body Fluids Contamination. J Prev Infect Control. 2016; 02 (02): 1-10.

[5] Zagade TB, Shinde MB. Impact of an educational program on knowledge among biomedical waste handlers regarding biomedical waste management newer guidelines 2016. J Crit Rev. 2020; 7 (13): 97-101.

[6] Chowdhury AKA, Roy T, Faroque A, Bachar SC, Asaduzzaman M, Nasrin N, et al. A comprehensive situation assessment of injection practices in primary health care hospitals in Bangladesh. BMC Public Health. 2011; 11.

[7] Shiferaw Y, Abebe T, Mihret A. Hepatitis B virus infection among medical aste handlers in Addis Ababa, Ethiopia. BMC Res Notes. 2011; 4.

[8] Derso S, Taye G, Getachew T, Defar A, Teklie H, Amenu K, et al. Biomedical waste disposal systems of health facilities in Ethiopia. Environ Heal Eng Manag [Internet]. 2018; 5 (1): 29 37. Available from: http://dx.doi.org/10.15171/EHEM.2018.05.

[9] Amsalu A, Worku M, Tadesse E, Shimelis T. The exposure rate to hepatitis $\mathrm{B}$ and $\mathrm{C}$ viruses among medical waste handlers in three government hospitals, southern Ethiopia. Epidemiol Health. 2016; 38: e2016001.

[10] Natha Mote B. Occupational and Environmental Health Hazards (Physical \&amp; Mental) Among Rag-Pickers in Mumbai Slums: A Cross-Sectional Study. Sci J Public Heal. 2016; 4 (1): 1.

[11] Jayakrishnan T, Jeeja M, Bhaskar R. Occupational health problems of municipal solid waste management workers in India. Int J Environ Health Eng. 2013; 2 (1): 42.

[12] Mohamed Soliman S, Ibrahim Ahmed A. Overview of biomedical waste management in selected Governorates in Egypt: A pilot study. Waste Manag. 2007; 27 (12): 1920-3.

[13] Salkin IF. Review of Health Impacts from Microbiological Hazards in Health-Care Wastes Prepared by. 2004.

[14] Alli BO. Fundamental principles of occupational health and safety. Vasa. 2008. 17-32 p.

[15] Eskezia D, Aderaw Z, Ahmed KY, Tadese F. Prevalence and associated factors of occupational injuries among municipal solid waste collectors in four zones of Amhara region, Northwest Ethiopia. BMC Public Health. 2016; 16 (1).
[16] Bogale D, Kumie A, Tefera W. Assessment of occupational injuries among Addis Ababa city municipal solid waste collectors: A cross-sectional study. BMC Public Health. 2014; 14 (1).

[17] Muluken A, Haimanot G, Mesafint M. Healthcare waste management practices among healthcare workers in healthcare facilities of Gondar town, Northwest Ethiopia. Heal Sci J. 2013; 7 (3): 315-26.

[18] Anozie OB, Lawani LO, Eze JN, Mamah EJ, Onoh RC, Ogah $\mathrm{EO}$, et al. Knowledge, attitude and practice of healthcare managers to medical waste management and occupational safety practices: Findings from southeast Nigeria. J Clin Diagnostic Res. 2017; 11 (3): IC01-4.

[19] Coker A, Sangodoyin A, Sridhar M, Booth C, Olomolaiye P, Hammond F. Medical waste management in Ibadan, Nigeria: Obstacles and prospects. Waste Manag [Internet]. 2009; 29 (2): 804-11. Available from: http://dx.doi.org/10.1016/j.wasman.2008.06.040.

[20] Shivalli S, Sowmyashree H. Occupational exposure to infection: A study on healthcare waste handlers of a tertiary care hospital in South India. J Assoc Physicians India. 2015; 63: 24-7.

[21] Deress T, Jemal M, Girma M, Adane K. Knowledge, attitude, and practice of waste handlers about medical waste management in Debre Markos town healthcare facilities, northwest Ethiopia. BMC Res Notes [Internet]. 2019; 12 (1): 1-7. Available from: https://doi.org/10.1186/s13104-0194174-7.

[22] Lakbala P, Azar FE, Kamali H. Needlestick and sharps injuries among housekeeping workers in hospitals of Shiraz, Iran. BMC Res Notes [Internet]. 2012; 5 (276). doi: 10.1186/17560500-5-276.

[23] Blenkharn JI, Odd C. Sharps injuries in healthcare waste handlers. Ann Occup Hyg. 2008; 52 (4): 281-6.

[24] Shiferaw Y, Abebe T, Mihret A. Hepatitis B virus infection among medical aste handlers in Addis Ababa, Ethiopia. BMC Res Notes [Internet]. 2011; 4 (1): 479. Available from: http://www.biomedcentral.com/1756-0500/4/479.

[25] Özer ZC, Efe E, Oncel S, Taskinsoy H, Ulker M. Hepatitis BHepatitis C seroprevalences and blunt-penetrating object injuries in housekeepers in Turkey: A survey study. J Clin Nurs. 2009; 18 (2): 294-300.

[26] Lanyuy GD, Jane FA, Wilfred FM. Medical waste management and disposal practices of health facilities in Kumbo East and Kumbo West health districts. Int J Med Med Sci. 2017; 9 (1): 1-11.

[27] Patwary MA, O'Hare WT, Sarker MH. Assessment of occupational and environmental safety associated with medical waste disposal in developing countries: A qualitative approach. Saf Sci. 2011; 49 (8-9): 1200-7. 